2

6 Xiaoming Wang ${ }^{\dagger}{ }^{\ddagger}, *$, Hong Ying ${ }^{\dagger}$, Wantong Zhao ${ }^{\dagger}$, Xionghan Feng ${ }^{\dagger}$, Wenfeng Tan ${ }^{\dagger}$, Kevin A.

7 Beyer ${ }^{\S}$, Qiaoyun Huang ${ }^{\dagger}$, Fan Liu ${ }^{\dagger}$, Mengqiang Zhu ${ }^{\ddagger}, *$

$8 \dagger$ Key Laboratory of Arable Land Conservation (Middle and Lower Reaches of Yangtze River),

9 Ministry of Agriculture and Rural Affairs, State Environmental Protection Key Laboratory of Soil

10 Health and Green Remediation, College of Resources and Environment, Huazhong Agricultural

11 University, Wuhan 430070, China

$12 \ddagger$ Department of Ecosystem Science and Management, University of Wyoming, Laramie, WY, 82071, 13 United States of America

$14 \S$ X-ray Science Division, Advanced Photon Source, Argonne National Laboratory, Lemont, Illinois 15 60439, United States

$16 *$ Corresponding author:

17 Xiaoming Wang: wangxm338@mail.hzau.edu.cn; Tel: +86 2787280271

18 Mengqiang Zhu: mzhu6@uwyo.edu; Tel.: +1 307-766-5523

19

20 This file includes the detailed experimental methods and procedures, two Tables, and nine Figures 


\section{Supplementary Experimental Methods}

\section{Text SI-1: Synthesis of Schwertmannite and Amorphous $\mathrm{FeAsO}_{4}$}

Schwertmannite was synthesized as the same procedures described in Wang et al. ${ }^{1}$ Briefly, oneliter deionized (DI) water was preheated to $60^{\circ} \mathrm{C}$ in an oil bath, followed with a quick addition of 5.4 g FeCl $3 \cdot 6 \mathrm{H}_{2} \mathrm{O}$ and $1.5 \mathrm{~g}$ of $\mathrm{Na}_{2} \mathrm{SO}_{4}$. Schwertmannite precipitated immediately and the obtained suspension was maintained at $60{ }^{\circ} \mathrm{C}$ for additional $12 \mathrm{~min}$ under stirring condition. After cooling to room temperature $\left(22{ }^{\circ} \mathrm{C}\right)$, the suspension was dialyzed for $\sim 7$ days. Amorphous $\mathrm{FeAsO}_{4}(\mathrm{AFA})$ were prepared at room temperature (RT) by rapid mixing of $250 \mathrm{~mL}$ of $0.2 \mathrm{M} \mathrm{Fe}\left(\mathrm{NO}_{3}\right)_{3} \cdot 9 \mathrm{H}_{2} \mathrm{O}$ solution with equal volumes of $0.3 \mathrm{M} \mathrm{Na}_{2} \mathrm{HAsO}_{4} \cdot 7 \mathrm{H}_{2} \mathrm{O}{ }^{2}$ The formed precipitates were further equilibrated for $3 \mathrm{~h}$ in the mother liquors without $\mathrm{pH}$ control. The obtained schwertmannite and AFA wet solids were cleaned, centrifuged, air dried, ground, and stored at $4{ }^{\circ} \mathrm{C}$. The morphology of the synthesized of schwertmannite was shown as follows:

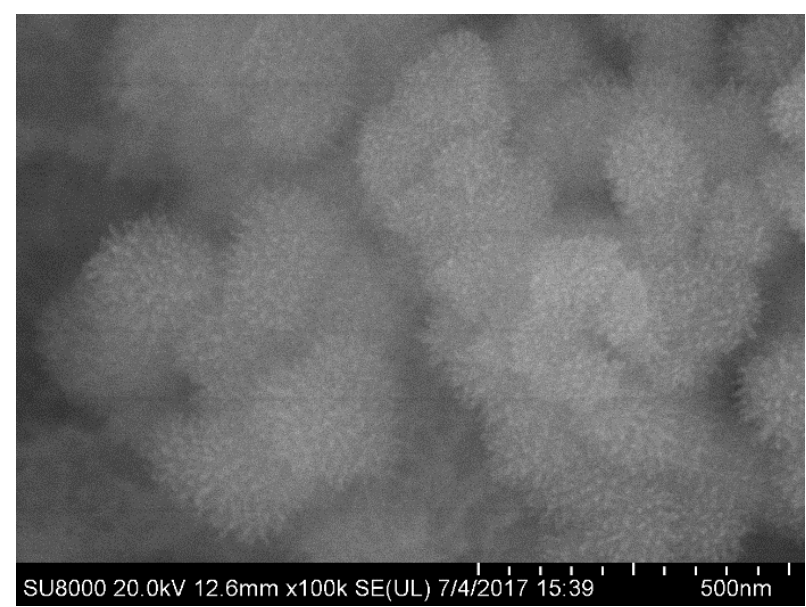

\section{Text SI-2. Cr(VI) and As(V) Sorption Kinetics.}

The sorption kinetics were evaluated by reacting $2.5 \mathrm{~g} / \mathrm{L}$ schwertmannite with $1 \mathrm{mM} \mathrm{Cr}(\mathrm{VI})$ or 1 $\mathrm{mM} \mathrm{As}(\mathrm{V})$ at $\mathrm{pH} 3.2$ or 5 and $\sim 21{ }^{\circ} \mathrm{C}$ in $50 \mathrm{mM} \mathrm{NaNO}_{3}$. In brief, $15 \mathrm{~g} / \mathrm{L}$ schwertmannite suspension was prepared by dispersing air-dried schwertmannite in $50 \mathrm{mM} \mathrm{NaNO}_{3}$ solution with ultra-sonication for $\sim 15$ min followed by overnight stirring, and the obtained suspension $\mathrm{pH}$ was $\sim 3.2$. Then, 100 
$\mathrm{mL}$ of $1.2 \mathrm{mM} \mathrm{Cr}(\mathrm{VI})$ or $\mathrm{As}(\mathrm{V})$ solution (pH 3.2 or 5) prepared with $50 \mathrm{mM} \mathrm{NaNO}$ was quickly

40 added to $20 \mathrm{~mL}$ of $15 \mathrm{~g} / \mathrm{L}$ schwertmannite suspension ( $\mathrm{pH}$ 3.2). Upon addition of $\mathrm{Cr}(\mathrm{VI})$ or $\mathrm{As}(\mathrm{V})$,

41 the suspension $\mathrm{pH}$ was kept at $\mathrm{pH} 3.2$ or $\mathrm{pH} 5$ by adding $0.2 \mathrm{M} \mathrm{NaOH}$ using a pH-STAT method

42 (Metrohm 907), and the reaction was lasted for $24 \mathrm{~h}$ under stirring. At pre-determined time intervals, a $2.5-\mathrm{mL}$ suspension was sampled and immediately filtered through a $0.22 \mu \mathrm{m}$ membrane syringe

44 filter.

\section{Text SI-3: Infrared Spectroscopy, X-ray Total Scattering XRD and PDF analyses}

For the collection of ATR-FTIR spectra, a small amount of sample was directly coated on the diamond crystal surface and pressed tightly by a pressure head. Thirty-two scans were collected against air and the diamond background for each sample with a resolution of $4 \mathrm{~cm}^{-1}$.

The measurement of X-ray total scattering data was performed at 11-ID-B at the Advanced Photon Source, using the rapid acquisition PDF method, ${ }^{3}$ employing a Perkin Elmer amorphous silicon detector. The image plate was exposed for $1.5 \mathrm{~s}$ and this was repeated 60 times for a total collection time of $90 \mathrm{~s}$ for each sample. The program Fit2D ${ }^{4}$ was used to integrate and convert the 2-D raw data to 1-D intensity versus wave vector $(Q)$. The PDF, G(r), was obtained from the raw 1$\mathrm{D}$ data using the program PDFgetX2. ${ }^{5}$ The data were truncated at momentum transfer of $\mathrm{Q}_{\max }=24$ $\AA^{-1}$.

\section{Text SI-4: Cr and As K-edge EXAFS Spectroscopy}

Cr and As K-edge EXAFS spectroscopy for the dried isotherm samples (1, 10, and $50 \mathrm{mM})$ and AFA were collected using a double crystal monochromator $\mathrm{Si}(111)$ in fluorescence mode at the beamline 1W1B of Beijing Synchrotron Radiation Facility (BSRF, Beijing, China). The electron beam energy was $2.5 \mathrm{GeV}$, with a maximum beam current of $250 \mathrm{~mA}$. The monochromator was 
62 calibrated by setting the first inflection point in a $\mathrm{Cr}$ foil to $5989 \mathrm{eV}$ or the L3-edge absorption 63 spectrum of an $\mathrm{Au}$ foil to $11919 \mathrm{eV}$. Two to three scans were conducted for each sample and the 64 averaged spectra were used. All EXAFS scans were processed using the program Athena. ${ }^{6}$ The 65 Autobk algorithm was applied for background removal using a linear pre-edge line between 150 and $6630 \mathrm{eV}$ before the edge, $\mathrm{E}_{0}$, and a normalization range from 150 to $690 \mathrm{eV}$ for $\mathrm{Cr}$ and 80 to $792 \mathrm{eV}$ for 67 As. The frequency cutoff parameter $\mathrm{R}_{\mathrm{bkg}}$ was set to 0.8 for $\mathrm{Cr}$ and 0.9 for As. The $\mathrm{k}$ weight in the background function determination was set to 3 , and the spline range used was $0-14.4 \AA^{-1}$.

Fourier transforms of normalized $\mathrm{k}^{3}$-weighted $\chi(\mathrm{k})$ data were calculated over a k range of 3 - 12 $70 \AA^{-1}$ using a Hanning window function. Least-squares fitting of $\mathrm{k}^{3}$-weighted $\mathrm{Cr}$ K-edge EXAFS 71 spectra (R-range: $1-3.2 \AA$ ) was then performed using the program Artemis ${ }^{6}$ to optimize the 72 degeneracy, half-path length, and mean-square displacement of backscattering atoms. Theoretical 73 amplitude and phase-shift files for the single-scattering (SS) and multiple-scattering (MS) paths, used 74 to model the Cr K-edge EXAFS spectra, were calculated with the program FEFF6 ${ }^{7}$ using the 75 structure of crocoite $\left(\mathrm{PbCrO}_{4}\right)^{8}$ but with Fe replacing the $\mathrm{Pb}$ sites. Two SS paths of $\mathrm{Cr}-\mathrm{O}$ and $\mathrm{Cr}-\mathrm{Fe}$ 76 were included. The Debye-Waller parameter of the Cr-Fe SS path for all samples was constrained to $77 \quad 0.003 \AA^{2} .{ }^{9}$ The double scattering Cr-O-O-Cr MS path was constrained by a path degeneracy of 12 78 and a mean half path length of a free $\mathrm{R}_{\mathrm{Cr}-\mathrm{O}-\mathrm{O}-\mathrm{Cr}}$ and a Debye-Waller parameter of $\sigma^{2} \mathrm{Cr}-\mathrm{O}$. The amplitude 79 reduction parameter $\left(\mathrm{S}_{0}^{2}\right)$ was set to 0.86 for all samples as in a previous study. ${ }^{9}$ 
81 Table S1. Shell-by-shell fitting parameters and the uncertainties determined from Cr K-edge EXAFS 82 spectra of the isotherm samples. The numbers in parentheses are error bars.

\begin{tabular}{|c|c|c|c|c|c|c|c|}
\hline Samples & Paths & $\mathrm{d}(\AA)$ & $\mathrm{CNs}^{a}$ & $\sigma^{2}\left(\AA^{2}\right)^{b}$ & $\Delta \mathrm{E}(\mathrm{eV})$ & R-factor (\%) & Red. $\chi^{2}$ \\
\hline \multirow{3}{*}{$\mathrm{pH} 5 \_1 \mathrm{mM}$} & $\mathrm{Cr}-\mathrm{O}$ & $1.65(1)$ & 4 & $0.0020(8)$ & $-2.0(16)$ & 1.4 & 17 \\
\hline & $\mathrm{Cr}-\mathrm{O}-\mathrm{O}$ & $3.05(5)$ & 12 & $0.0020(8)$ & & & \\
\hline & $\mathrm{Cr}-\mathrm{Fe}$ & $3.34(4)$ & $0.5(3)$ & 0.003 & & & \\
\hline \multirow{3}{*}{$\mathrm{pH} 5 \_10 \mathrm{mM}$} & $\mathrm{Cr}-\mathrm{O}$ & $1.65(1)$ & 4 & $0.0025(3)$ & $-1.9(14)$ & 1.0 & 36 \\
\hline & $\mathrm{Cr}-\mathrm{O}-\mathrm{O}$ & $3.04(4)$ & 12 & $0.0025(3)$ & & & \\
\hline & $\mathrm{Cr}-\mathrm{Fe}$ & $3.35(4)$ & $0.4(2)$ & 0.003 & & & \\
\hline \multirow{3}{*}{$\mathrm{pH} 5 \_50 \mathrm{mM}$} & $\mathrm{Cr}-\mathrm{O}$ & $1.65(1)$ & 4 & $0.0026(3)$ & $-1.9(15)$ & 1.1 & 39 \\
\hline & $\mathrm{Cr}-\mathrm{O}-\mathrm{O}$ & $3.04(5)$ & 12 & $0.0026(3)$ & & & \\
\hline & $\mathrm{Cr}-\mathrm{Fe}$ & $3.34(3)$ & $0.4(3)$ & 0.003 & & & \\
\hline \multirow{3}{*}{$\mathrm{pH} 3 \_10 \mathrm{mM}$} & $\mathrm{Cr}-\mathrm{O}$ & $1.65(1)$ & 4 & $0.0032(4)$ & $-1.4(18)$ & 1.7 & 39 \\
\hline & $\mathrm{Cr}-\mathrm{O}-\mathrm{O}$ & $3.06(6)$ & 12 & $0.0032(4)$ & & & \\
\hline & $\mathrm{Cr}-\mathrm{Fe}$ & $3.34(6)$ & $0.3(3)$ & 0.003 & & & \\
\hline \multirow{3}{*}{ pH 3_50 mM } & $\mathrm{Cr}-\mathrm{O}$ & $1.65(1)$ & 4 & $0.0031(3)$ & $-2.7(16)$ & 1.3 & 34 \\
\hline & Cr-O-O & $3.03(5)$ & 12 & $0.0031(3)$ & & & \\
\hline & $\mathrm{Cr}-\mathrm{Fe}$ & $3.35(6)$ & $0.3(3)$ & 0.003 & & & \\
\hline
\end{tabular}

${ }^{a}$ Coordination numbers (CNs) of $\mathrm{Cr}-\mathrm{O}$ and $\mathrm{Cr}-\mathrm{O}-\mathrm{O}$ are, respectively, fixed at 4 and 12 .

${ }^{b}$ Debye-Waller factors $\left(\sigma^{2}\right)$ of As-O and As-O-O were set to the same, and $\sigma^{2}$ of $\mathrm{Cr}-\mathrm{Fe}$ for all samples was constrained to $0.003 \AA^{2}$. 
84 Table S2. The structural parameters of sulfate in schwertmannite determined from S K-edge EXAFS 85 fitting for the selected $\mathrm{As}(\mathrm{V})$ and $\mathrm{Cr}(\mathrm{VI})$ sorption isotherm samples at $\mathrm{pH}$ 3.2. The numbers in 86 parentheses are error bars.

\begin{tabular}{|c|c|c|c|c|c|c|c|c|}
\hline \multirow[b]{2}{*}{ Samples } & \multicolumn{3}{|l|}{$\mathrm{S}-\mathrm{O}$} & \multicolumn{3}{|l|}{$\mathrm{S}-\mathrm{Fe}$} & \multirow[b]{2}{*}{$\begin{array}{l}\Delta \mathrm{E} \\
(\mathrm{eV})\end{array}$} & \multirow[b]{2}{*}{$\begin{array}{l}\text { R-factor } \\
(\%)\end{array}$} \\
\hline & $\mathrm{d}(\AA)$ & $\mathrm{CN}^{a}$ & $\sigma^{2}\left(\AA^{2}\right)$ & $\mathrm{d}(\AA)$ & $\mathrm{CN}$ & $\sigma^{2}\left(\AA^{2}\right)^{b}$ & & \\
\hline blank & $1.483(4)$ & 4 & $0.0016(2)$ & $3.22(2)$ & $1.2(4)$ & 0.006 & $11(2)$ & 0.7 \\
\hline $1 \mathrm{mM} \mathrm{As}$ & $1.485(7)$ & 4 & $0.0012(3)$ & $3.24(5)$ & $0.9(8)$ & 0.006 & $12(3)$ & 2.7 \\
\hline $10 \mathrm{mM} \mathrm{As}$ & $1.493(8)$ & 4 & 0.0007 (4) & $3.25(6)$ & $1.0(9)$ & 0.006 & $14(3)$ & 3.0 \\
\hline $1 \mathrm{mM} \mathrm{Cr}$ & $1.488(8)$ & 4 & 0.0015 (4) & $3.24(5)$ & $0.9(8)$ & 0.006 & $12(3)$ & 3.0 \\
\hline $10 \mathrm{mM} \mathrm{Cr}$ & $1.491(9)$ & 4 & 0.0019 (5) & $3.25(6)$ & $0.9(9)$ & 0.006 & 14 (4) & 4.2 \\
\hline
\end{tabular}



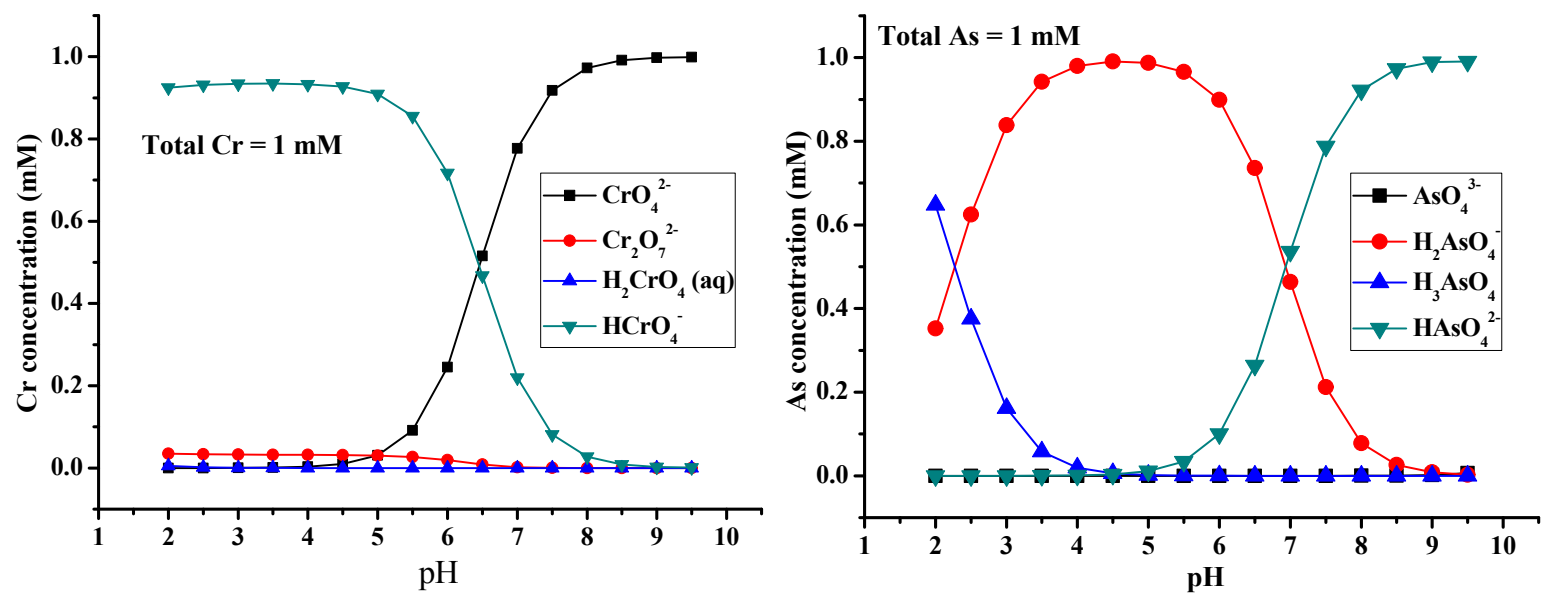

89 Figure S1. The speciation distribution of $\mathrm{Cr}(\mathrm{VI})$ and $\mathrm{As}(\mathrm{V})$ at different $\mathrm{pHs}$ with total $\mathrm{Cr}$ or $\mathrm{As}$ 90 concentration of $1 \mathrm{mM}$.

91 
92

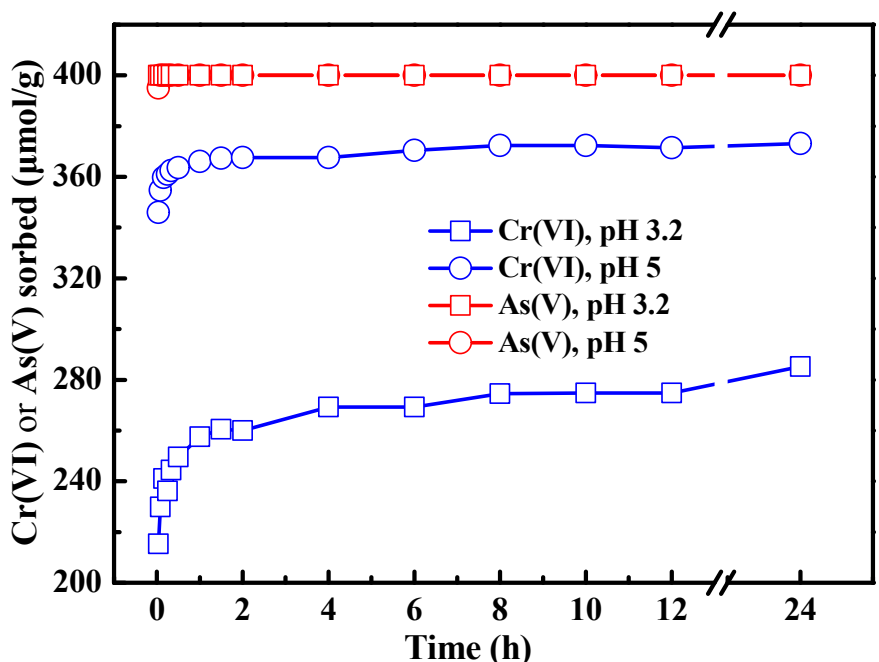

Figure S2. The $\mathrm{Cr}(\mathrm{VI})$ and $\mathrm{As}(\mathrm{V})$ sorption kinetics on schwertmannite at $\mathrm{pH} 3.2$ and $\mathrm{pH} 5$.

The sorption kinetics indicate that for $1 \mathrm{mM} \mathrm{Cr}(\mathrm{VI})$ or $\mathrm{As}(\mathrm{V})$ at both $\mathrm{pH} 3.2$ and 5, most $\mathrm{Cr}(\mathrm{VI})$ sorption occurs within the first $1 \mathrm{~h}$ and slightly increases afterward, while As(V) is quickly depleted within a few minutes. Although high $\mathrm{pH}$ disfavors $\mathrm{Cr}(\mathrm{VI})$ sorption on Fe oxides, ${ }^{10}$ removal of $\mathrm{Cr}(\mathrm{VI})$ from solution by schwertmannite is more and also faster at $\mathrm{pH} 5$ than at $\mathrm{pH} 3.2$, ascribed to more readily anionic exchange of sulfate at a higher $\mathrm{pH} .{ }^{11-13}$

100 

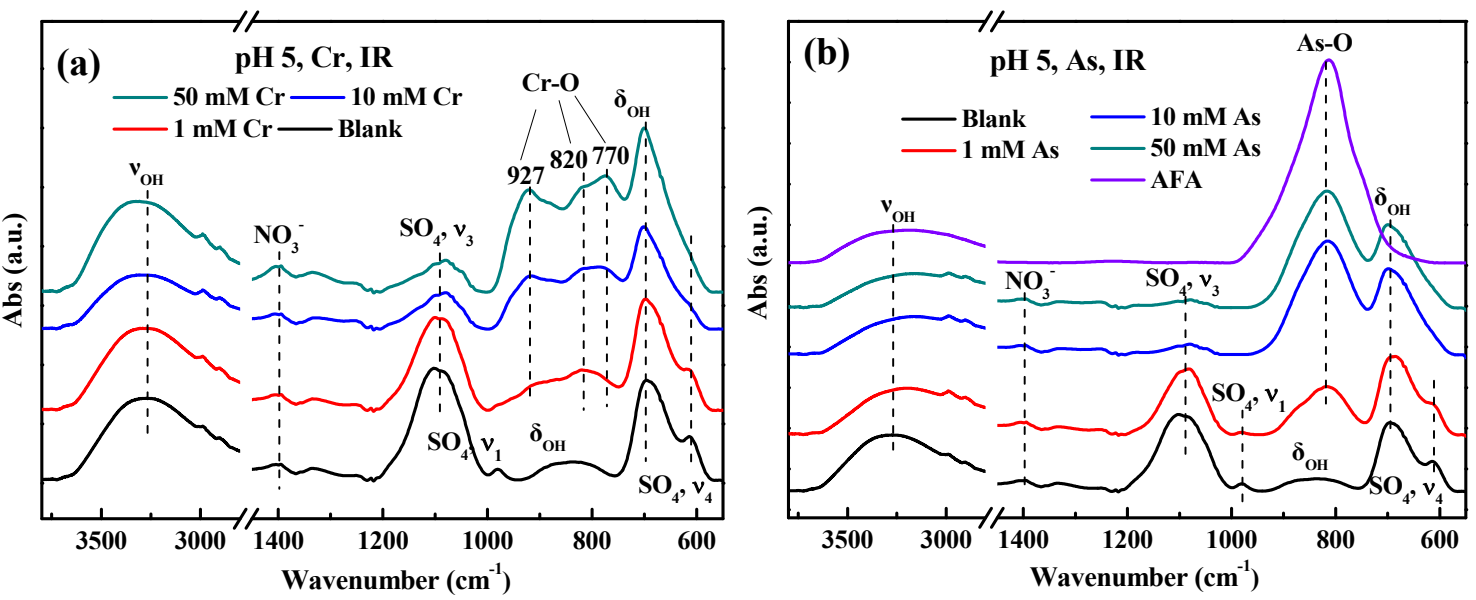

Figure S3. ATR-FTIR spectra of the air dried sorption isotherm samples for Cr(VI) (a) and As(V)

(b) at $\mathrm{pH} 5$ in the background electrolyte of $50 \mathrm{mM} \mathrm{NaNO}_{3}$ solutions, and the spectra of amorphous $\mathrm{FeAsO}_{4}(\mathrm{AFA})$ was included as a reference. 

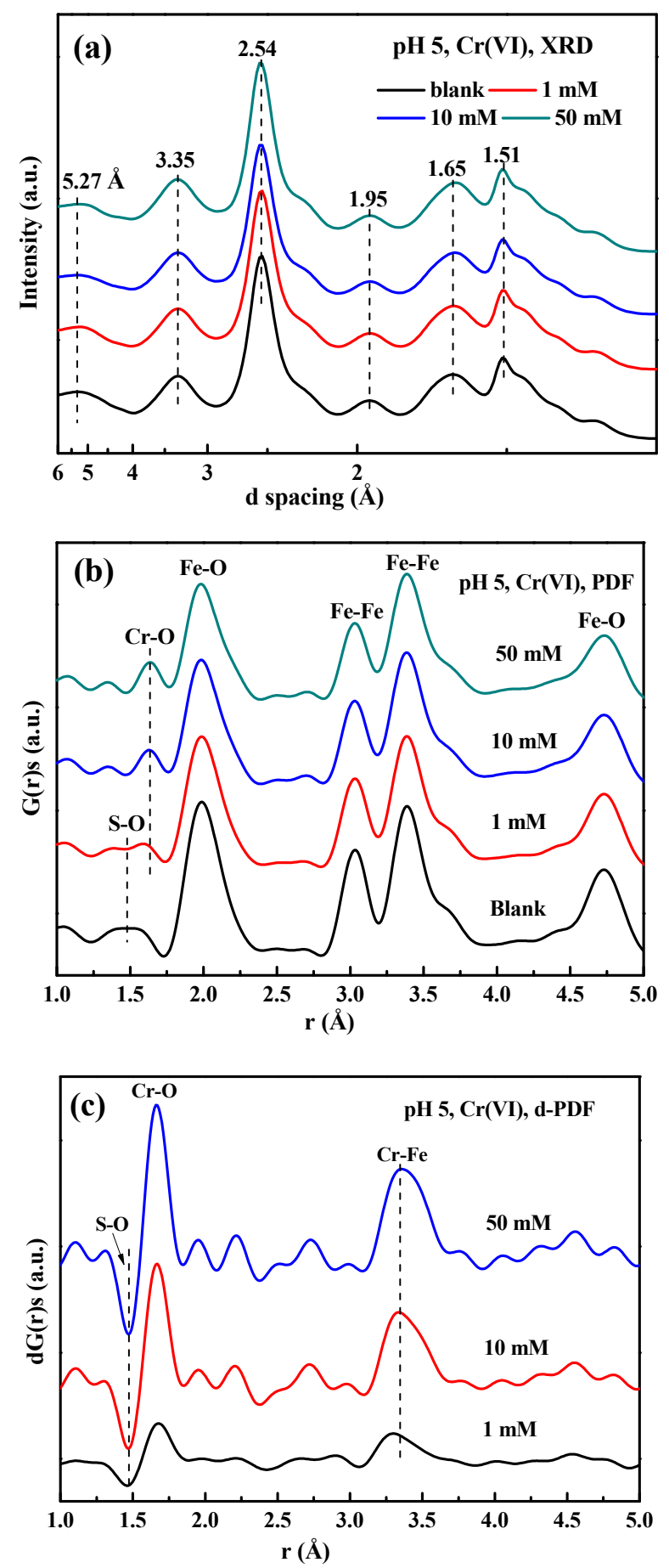

109 Figure S4. Synchrotron X-ray diffraction (XRD) (a), pair distribution functions (b), and differential 110 pair distribution functions (d-PDFs, c) obtained by minimizing the Fe-O peak at $\sim 4.73 \AA$ of the $111 \mathrm{Cr}(\mathrm{VI})$ sorption isotherm samples at $\mathrm{pH} 5$. 

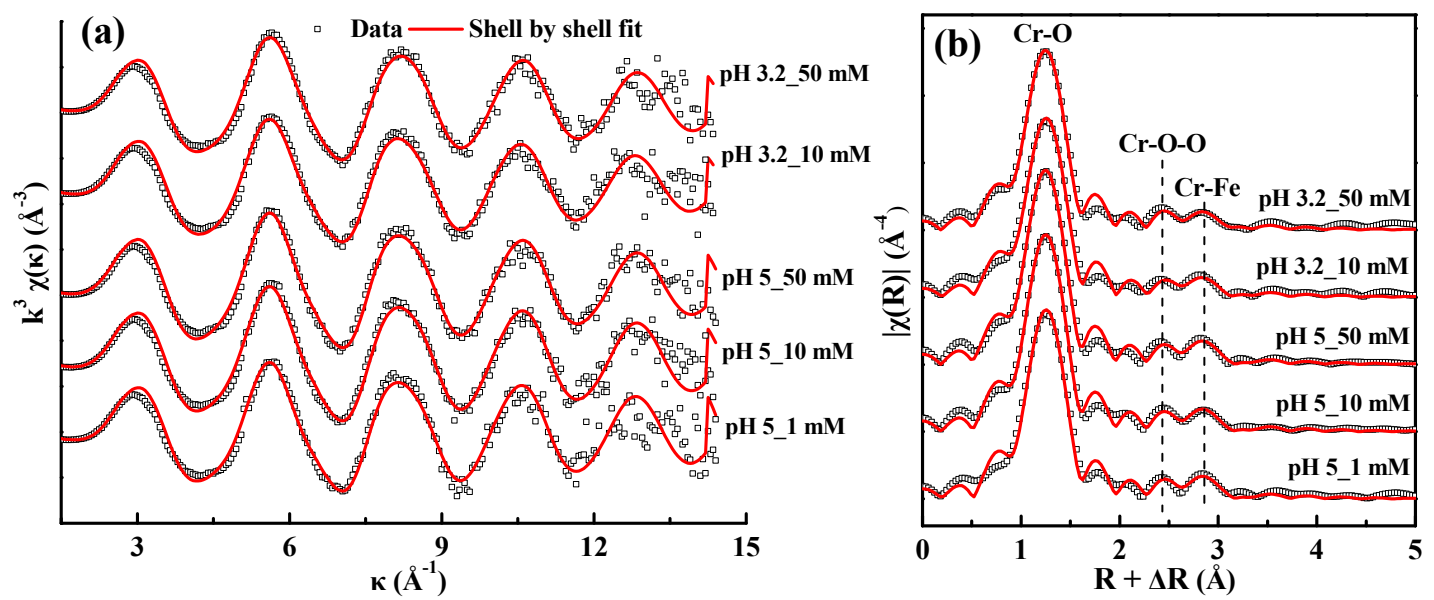

114 Figure S5. Cr K-edge EXAFS spectroscopy for the data (blank square) and shell-by-shell model fits

115 (red lines) for Cr(VI) sorption isotherm samples (uncorrected for phase shifts): $\mathrm{k}^{3}$-weighted $\chi(\mathrm{k})$

116 spectra (a) and Fourier transform magnitude (b), and the fitted parameters are summarized in Table 117 S1. 

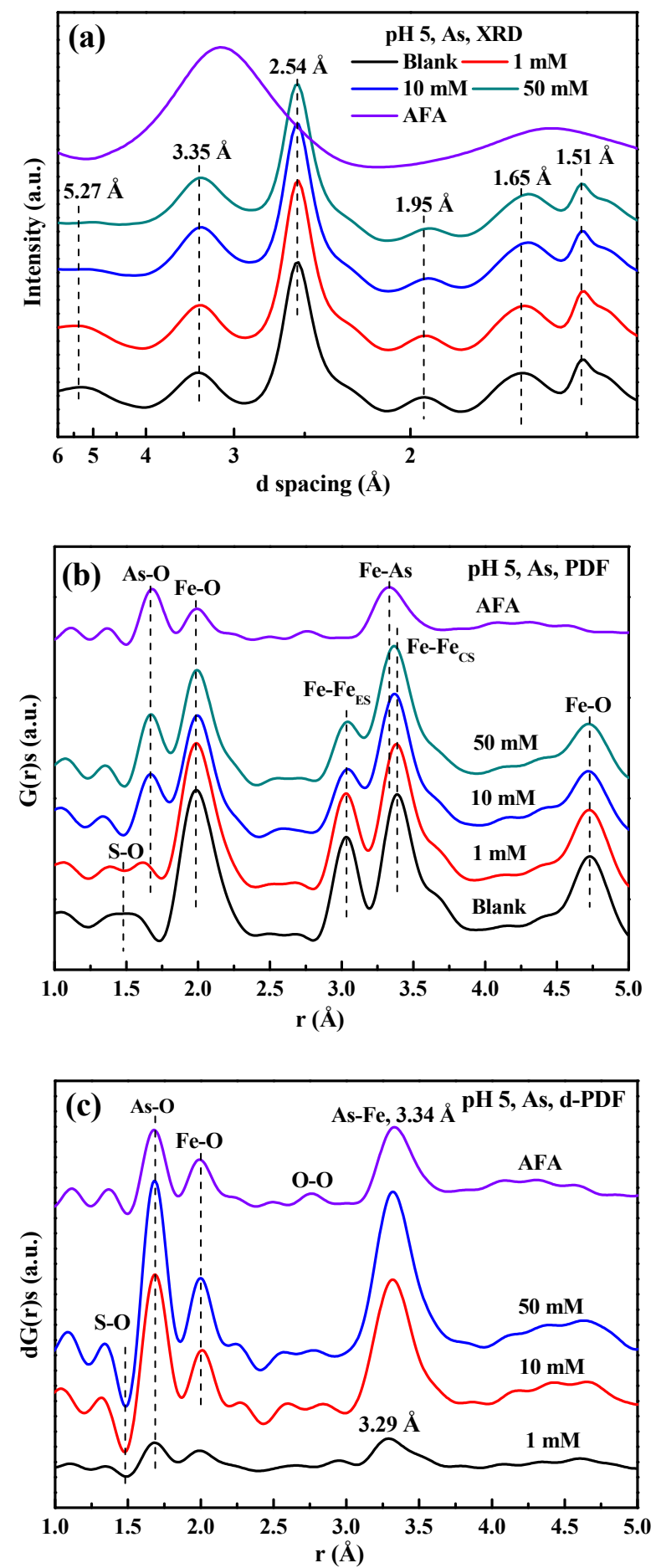

Figure S6. Synchrotron X-ray diffraction (XRD) (a), pair distribution functions (b), and differential

123 pair distribution functions (d-PDFs, c) obtained by minimizing the Fe-O peak at $\sim 4.73 \AA$ of the $\mathrm{As}(\mathrm{V})$

124 sorption isotherm samples at $\mathrm{pH} 5$. 

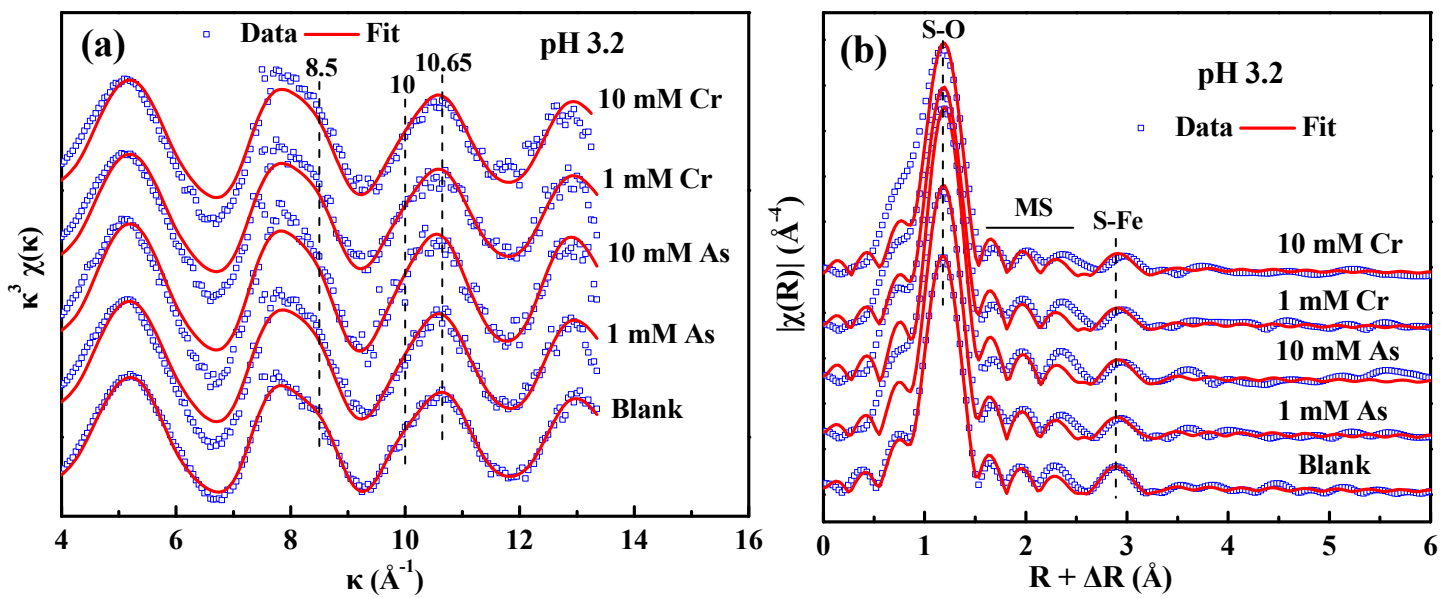

127 Figure S7. Sulfur K-edge EXAFS spectra and their fits for the selected As(V) and Cr(VI) sorption isotherm samples at $\mathrm{pH} 3.2$, and the fitted parameters are summarized in Table S2.

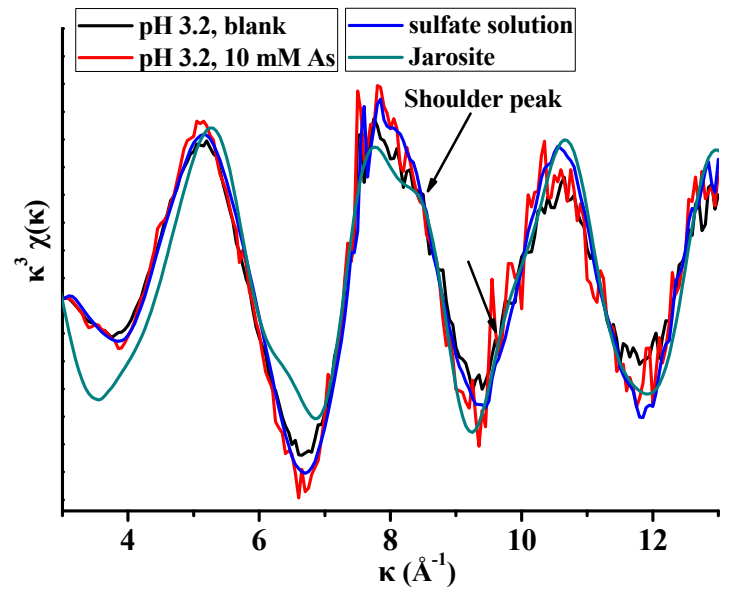

131 Figure S8. Sulfur K-edge EXAFS spectra of isotherms samples with that of sulfate solution and 132 jarosite as for comparison in $\mathrm{k}$ space. 


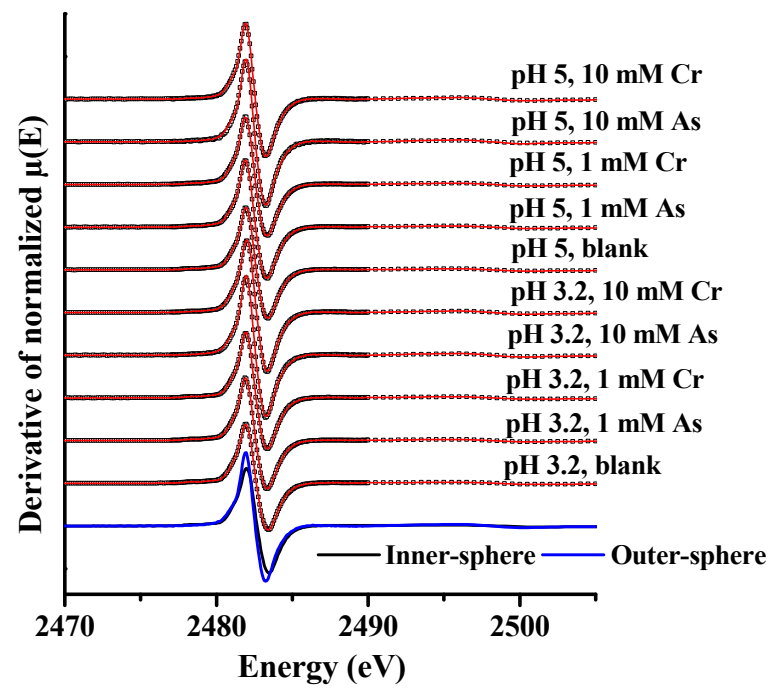

Figure S9. Data (black dot) and their linear combination fits (red line) of individual S K-edge XANES spectra to determine the relative fractions of inner- and outer- sphere complexes of the sorption isotherm samples at different $\mathrm{pHs}$ and $\mathrm{Cr}(\mathrm{VI})$ or $\mathrm{As}(\mathrm{V})$ loadings (data and fits of $50 \mathrm{mM}$ were not shown), the derivative of the normalized $\mu(\mathrm{E})$ was used to do the LCF analysis because it gets a better fit than the spectra of normalized $\mu(\mathrm{E})$.

\section{References}

1. Wang, X.; Gu, C.; Feng, X.; Zhu, M. Sulfate local coordination environment in schwertmannite. 143 Environ. Sci. Technol. 2015, 49, 10440-10448.

144 2. Mikutta, C.; Schroder, C.; Michel, F. M. Total X-ray scattering, EXAFS, and Mössbauer 145 spectroscopy analyses of amorphous ferric arsenate and amorphous ferric phosphate. Geochim. 146 Cosmochim. Acta 2014, 140, 708-719.

147 3. Chupas, P. J.; Qiu, X.; Hanson, J. C.; Lee, P. L.; Grey, C. P.; Billinge, S. J. L. Rapid-acquisition 148 pair distribution function (RA-PDF) analysis. J. Appl. Crystallogr. 2003, 36, 1342-1347.

149 4. Hammersley, A. P. ESRF Internal Report, ESRF98HA01T, FIT2D V9.129 Reference Manual V3.1. 1501998.

151 5. Qiu, X.; Thompson, J. W.; Billinge, S. J. L. PDFgetX2: a GUI-driven program to obtain the pair 152 distribution function from X-ray powder diffraction data. J. Appl. Crystallogr. 2004, 37, 678-678.

153 6. Ravel, B.; Newville, M. ATHENA, ARTEMIS, HEPHAESTUS: data analysis for X-ray 154 absorption spectroscopy using IFEFFIT. J. Synchrotron Radiat. 2005, 12, 537-541.

155 7. Ankudinov, A. L.; Rehr, J. J. Relativistic calculations of spin dependent X-ray absorption spectra. 156 Phys. Rev. B 1997, 56, 1712-1715. 
157 8. Quareni, S.; De Pieri, R. A three-dimensional refinement of the structure of crocoite, $\mathrm{PbCrO}_{4}$. Acta 158 Crystallogr. 1965, 19, 287-289.

159 9. Johnston, C. P.; Chrysochoou, M. Mechanisms of chromate adsorption on hematite. Geochim. 160 Cosmochim. Acta 2014, 138, 146-157.

161 10. Grossl, P. R.; Eick, M.; Sparks, D. L.; Goldberg, S.; Ainsworth, C. C. Arsenate and chromate 162 retention mechanisms on goethite .2. Kinetic evaluation using a pressure-jump relaxation technique. 163 Environ. Sci. Technol. 1997, 31, 321-326.

164 11. Burton, E. D.; Bush, R. T.; Johnston, S. G.; Watling, K. M.; Hocking, R. K.; Sullivan, L. A.; 165 Parker, G. K. Sorption of arsenic(V) and arsenic(III) to schwertmannite. Environ. Sci. Technol. 2009, 166 43, 9202-9207.

167 12. Zhang, Z.; Guo, G.; Li, X.; Zhao, Q.; Bi, X.; Wu, K.; Chen, H. Effects of hydrogen-peroxide 168 supply rate on schwertmannite microstructure and chromium(VI) adsorption performance. J. Hazard. 169 Mater. 2019, 367, 520-528.

170 13. Yu, C.; Zhang, J.; Wu, X.; Lan, Y.; Zhou, L. Cr(VI) removal by biogenic schwertmannite in 171 continuous flow column. Geochem. J. 2014, 48, 1-7.

172 